\title{
Acute Mediastinitis as a Complication of Epstein-Barr Virus
}

\author{
Taryn Lloyd, HBSc*; Vu Kiet Tran, $\mathrm{MD}^{*}{ }^{\dagger}$
}

\section{ABSTRACT}

Acute mediastinitis is a rare, potentially life-threatening condition that is most commonly seen as a complication of esophageal perforations or cardiac surgery. The term "descending necrotizing mediastinitis" (DNM) is used to describe oropharyngeal infections that spread to the mediastinum, most commonly following odontogenic infections, peritonsillar or retropharyngeal abscesses, cervical lymphadenitis, trauma, or endotracheal intubation. Infectious mononucleosis is another rare cause of DNM. The mortality of acute mediastinitis is high, while the mortality for DNM is even higher. Major determinants of mortality are delayed diagnosis and/or treatment. While DNM is seen infrequently, its severe nature makes it essential that emergency physicians consider the diagnosis in patients presenting with upper respiratory infections, chest pain, and systemic symptoms, and also in patients with a recent diagnosis of EBV, in order to mitigate a high rate of morbidity and mortality.

\section{RÉSUMÉ}

La médiastinite aiguë est une maladie rare, potentiellement mortelle, qui résulte la plupart du temps d'une perforation de I'œsophage ou d'une opération cardiaque. L'expression " médiastinite nécrosante descendante " (MND) fait référence aux infections oropharyngées, qui se propagent au médiastin; il s'agit en général d'infections odontogènes, de phlegmons périamygdaliens ou d'abcès rétropharyngiens, de lymphadénite cervicale, de traumas ou d'intubations endotrachéales. La mononucléose infectieuse donne rarement lieu à une MND. Si la mortalité attribuable à la médiastinite aiguë est élevée, celle attribuable à la MND l'est encore plus. Les principaux déterminants de la mortalité sont un retard dans la pose du diagnostic ou la mise en route du traitement. Bien que les cas de MND soient rares, la gravité de la maladie exige que les médecins d'urgence envisagent le diagnostic chez les patients présentant une infection des voies respiratoires supérieures, des douleurs thoraciques et des symptômes généraux ainsi que chez les patients chez qui une infection à virus Epstein-Barr a été diagnostiquée depuis peu, afin d'abaisser le taux élevé de morbidité et de mortalité.

Keywords: EBV, Acute Necrotizing Mediastinitis, Descending Necrotizing Mediastinitis

\section{CASE REPORT}

A previously healthy 39-year-old male initially presented to the emergency department (ED) with an upper respiratory tract infection characterized by cough, nasal congestion, rhinorrhea, bilateral earache with drainage, sore throat, nausea and vomiting. On physical examination, he was found to have bilateral ear effusions and upper airway congestion. He had normal heart sounds and his lungs had equal and clear air entry bilaterally. He had a temperature of $37^{\circ} \mathrm{C}\left(98.6^{\circ} \mathrm{F}\right)$, a heart rate of 113 beats per minute, respiratory rate of 16 breaths per minute, blood pressure of $114 / 79 \mathrm{~mm} \mathrm{Hg}$, and an oxygen saturation of $98 \%$ on room air. His chest $\mathrm{x}$-ray was normal. He was diagnosed with a suspected viral illness, likely influenza, and discharged home. Two days later, this patient returned to the ED with new fever, increasing shortness of breath, pleuritic chest pain, jaundice, and right upper quadrant abdominal pain. The chest $x$-ray revealed a prominent mediastinum consistent with mediastinal lymphadenopathy and no pleural effusions. Heart size was normal and the lungs were clear. Initial blood work was within normal limits. On the second day, the patient developed elevations in liver enzymes and bilirubin levels. The abdominal ultrasound found no explanation for the patient's pain and no evidence of cholangitis; however, it did show a mildly enlarged spleen without focal lesions. A computed tomography (CT) of the thorax revealed infiltrating soft tissue throughout the mediastinum suggestive of acute mediastinitis, extensive thickening of the esophageal wall without perforation, and a small right pleural effusion with adjacent right lower lobe atelectasis. The patient was admitted to hospital with a diagnosis of suppurative mediastinitis. Further imaging on admission day two revealed bilateral pleural effusions confirmed by abdominal

From the *University of Toronto, Toronto, ON; and HUniversity Health Network, University of Toronto, Toronto, ON.

Correspondence to: Dr. Vu Kiet Tran, 22 Highview Crescent, Richmond Hill, Ontario, L4B 2T8; Email: Vukiet.tran@rogers.com 
ultrasound. On admission day eight, CT of the chest revealed increased pleural effusions, and due to the lack of contrast leak, ruled out esophageal rupture as a likely cause. While in hospital the patient underwent procedural drainage of the mediastinum with thoracostomy tubes. Bacterial and fungal cultures were negative. The pleural effusions were also drained on admission day nine. Bacterial and fungal cultures of the pleural fluid were negative. The patient was treated with piperacillin and tazobactam while in hospital, and subsequently amoxicillin and clavulanic acid for a period of three weeks, with full resolution of his symptoms. The patient spent a total of 15 days in hospital.

Investigations done while in hospital included fungal serologies, bacterial cultures of mediastinum fluid, pleural fluid, blood, and urine, hepatitis A, B, C, and HIV serologies, respiratory viral RT-PCR for influenza $\mathrm{A}, \mathrm{B}$, and H1N1, as well as EBV (Epstein-Barr virus) DNA PCR. All investigations were negative except for the EBV DNA, which came back positive. HIV serology testing was inconclusive. On follow-up two months after hospital discharge, the EBV DNA became undetectable, the monospot and early antigen $\mathrm{IgG}$ remained negative, while the VCA IgG antibody and the EBNA IgG antibody were positive, all conclusive of a previous EBV infection. At two months post-discharge, the patient remained well from a symptomatic perspective. A chest $\mathrm{x}$-ray done at one year postinfection showed a clear mediastinum and lungs.

\section{DISCUSSION}

EBV is generally a self-limited, mild illness characterized by fever, pharyngitis, and lymphadenopathy. ${ }^{1,2}$ Descending necrotizing mediastinitis (DNM) is an unusual complication of EBV. A search of the literature revealed only three documented cases of DNM in relation to infectious mononucleosis. All three cases described EBV with a documented secondary bacterial infection causing DNM. ${ }^{1-3}$

DNM more commonly refers to the spread of oropharyngeal infections to the mediastinum. Almost exclusively, this occurs in patients following odontogenic infections, peritonsillar or retropharyngeal abscesses, cervical lymphadenitis, trauma, or endotracheal intubation. ${ }^{4}$ Infectious mononucleosis, most commonly caused by EBV, rarely causes respiratory complications. $^{2,3}$ These respiratory complications include upper airway obstruction from tonsillar enlargement or a pharyngeal abscess, bilateral hilar adenopathy, interstitial pneumonitis, superimposed bacterial pneumonia, and septic thrombophlebitis. Another rare complication of EBV is the development of bilateral anaerobic empyemas. It is speculated, by Andrianakis et al., that this can occur through two potential mechanisms. ${ }^{2}$ The first proposed mechanism is through the development of septic thrombophlebitis of the jugular veins, resulting in septic emboli that invade the mediastinum. This is known as Lemierre syndrome. A second proposed mechanism is direct spread of a pharyngeal abscess through the alar and prevertebral fasciae of the neck. Through this deep neck space, infectious culprits gain direct access to the mediastinum and pleural space, resulting in empyemas and acute mediastinitis. In our reported case of acute mediastinitis, all bacterial cultures were negative. Despite this, we hypothesize that the mediastinitis was caused by a secondary bacterial infection that may have gone undetected due to the early initiation of antibiotic therapy.

The mortality of descending necrotizing mediastinitis is as high as $40-50 \% .^{5}$ Early diagnosis has been shown to reduce mortality. ${ }^{6}$ The early contrast-enhanced CT of the neck and thorax is the single most important tool for early diagnosis of DNM. ${ }^{5-8}$ Features of DNM on CT include increased density of the adipose tissue, myositis, cervical lymphadenopathy, and/or mediastinal fluid collection (with or without gas). ${ }^{8}$ Bilateral empyemas seen on CT are pathognomonic for acute mediastinitis and treatment should begin immediately. ${ }^{3}$ Emergency physicians must consider a diagnosis of DNM and have a low threshold for CT scanning in patients who present systemically unwell with chest pain, upper respiratory tract infection, and a recent diagnosis of EBV.

\section{CONCLUSION}

DNM is an infrequent but serious disease with high mortality. It is most commonly seen in patients following odontogenic infections, peritonsillar or retropharyngeal abscesses, cervical lymphadenitis, trauma, or endotracheal intubation. We describe a case of DNM secondary to infectious mononucleosis caused by EBV. Emergency physicians should consider a diagnosis of DNM in patients presenting systemically unwell with chest pain, upper respiratory tract 
infections, or with a recent diagnosis of EBV. If DNM is clinically suspected, CT should not be delayed.

Competing Interests: Dr. Vu Kiet reports personal fees from Eli Lilly Canada, personal fees from Best Doctors Canada, and personal fees from Gamma-Dynacare Medical Laboratories.

\section{REFERENCES}

1. Nguyen D, Kenny J, Chin M, et al. A sore throat complicated by pneumomediastinum. Am 7 Respir Crit Care Med, 185;2012:A5946.

2. Andrianakis I, Kotanidou A, Pitaridis $M$, et al. Lifethreatening bilateral empyema and mediastinitis complicating infectious mononucleosis. Intensive Care Med 2002; 28(5):663-4, doi:10.1007/s00134-002-1270-1.
3. Kopec S, Irwin R, Mello C, et al. Bilateral anaerobic empyemas complicating infectious mononucleosis. Chest 1997;112(3):833-5.

4. Alsoub H, Chacko K. Descending necrotizing mediastinitis. Postgrad Med 7 1995;71(832):98-101, doi:10.1136/pgmj. 71.832.98.

5. Estrera A, Landay M, Grisham J, et al. Descending necrotizing mediastinitis. Surg Gynecol Obstet 1983;157(6):545-52.

6. Sancho L, Minamoto H, Fernandez A, et al. Descending necrotizing mediastinitis: a retrospective surgical experience. Eur 7 Cardiothorac Surg 1999;16(2):200-5.

7. Novellas S, Kechabtia K, Chevallier P, et al. Descending necrotizing mediastinitis: A rare pathology to keep in mind. Clin Imaging 2005;29(2):138-40.

8. Scaglione M, Pinto A, Giovine S, et al. CT features of descending necrotizing mediastinitis-a pictorial essay. Emerg Radiol 2007;14(2):77-81. 